\title{
Unilateral non traumatic vertebral artery dissection with cervical spinal cord infarction
}

\author{
Dissecção unilateral da artéria vertebral não traumática com infarto da medula \\ espinhal cervical
}

Patricia Gushiken Takahashi, Rubens Gisbert Cury, Camila Galvão Lopes, Mateus Mistieri Simabukuro, Paulo Euripedes Marchiori

A 45-year old male patient with diabetes presented neck pain with paresthesia and paresis in upper limbs. Physical examination: proximal paraparesis, hyporeflexia and hypoesthesia in the upper limbs. MRI: ischemia in the right hemi-spinal cord (Fig 1), associated to right vertebral artery (VA) dissection (Fig 2).
Although more frequently VA dissection causes transient ischemic attack or stroke $e^{1}$ there are few reported cases of ischemia of the cervical cord. VA branches may feed the cervical part of the anterior spinal artery on one or both sides and its occlusion by VA dissection may cause hypoperfusion in this territory².
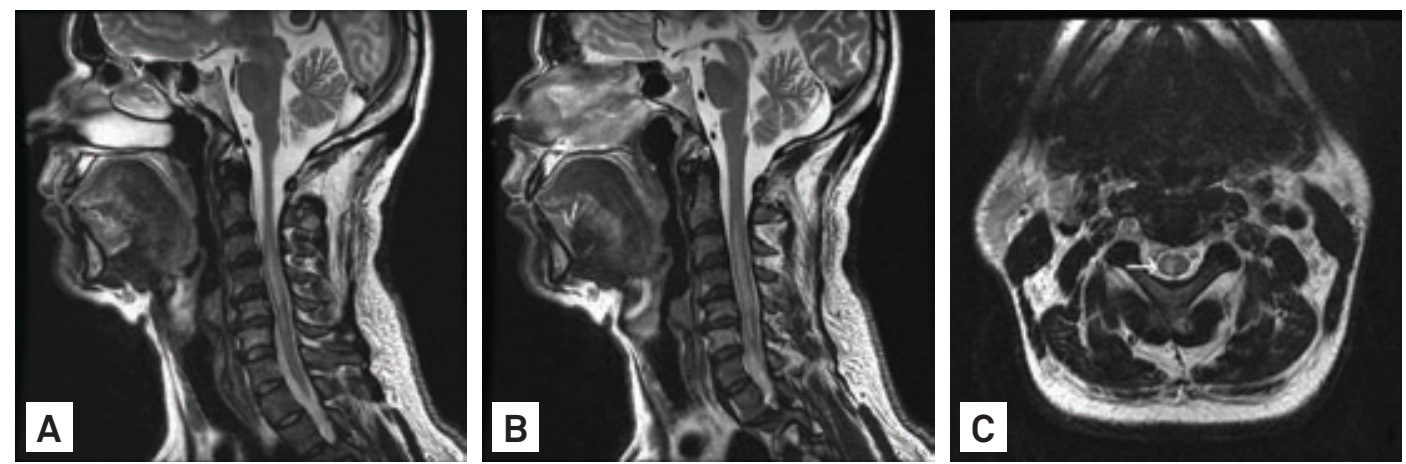

Fig 1. Sagittal T2-weighted MRI with hypersignal in spinal cord at levels C2-C6, without expansion effect (A and B). Axial T2weighted MRI with hypersignal in right hemi-spinal cord (C).
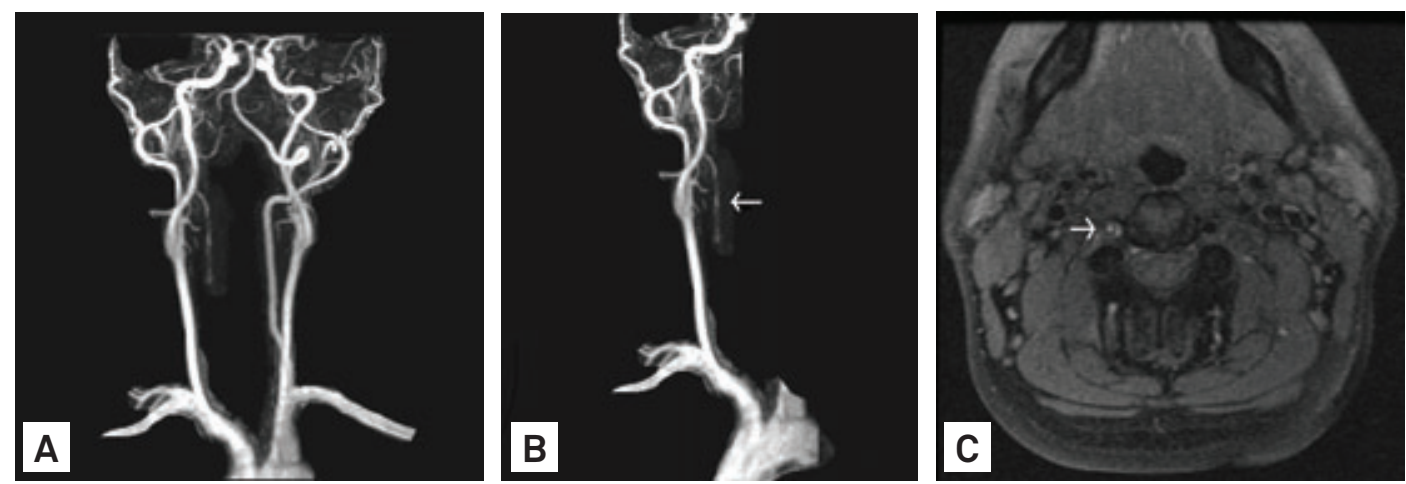

Fig 2. MR angiography showing right vertebral artery not characterized until half of the $V 2$ segment, with sequential stenoses,

suggesting arterial dissection (A and B), and axial T1 fat suppression sequence with luminal hypersignal, consistent with thrombus (C).

\section{References}

Arnold M, Bousser MG. Clinical manifestations of vertebral artery dissection. Front Neurol Neurosci 2005;20:77-86.
Machnowska M, Moien-Afshari F, Voll C, Wiebe S. Partial anterior cervical cord infarction following vertebral artery dissection. Can J Neurol Sci 2008;35:674-677. 